\title{
E Female authorship in neurosurgical journals: what remains to be done
}

\author{
Shelly D. Timmons, MD, PhD \\ Department of Neurological Surgery, Indiana University School of Medicine and Indiana University Health, Indianapolis, Indiana
}

$\mathrm{M}$ ARIE Curie once stated in a letter to her brother, "One never notices what has been done; one can only see what remains to be done." In their article "Increases in female academic productivity and female mentorship highlight sustained progress in previously identified neurosurgical gender disparities," Taha et al. describe "what has been done" in recent years vis-àvis women publishing in neurosurgical journals, reporting steady increases in the proportion of women authors. ${ }^{2}$ As a result, they pave the way for our profession to delve further into the issue, clarifying the reasons for differences in authorship by gender, both historically and currently, the implications of publication on academic advancement and the potential for evolution in other aspects of neurosurgical academia.

The group utilized big data techniques to assess female gender representation as first and last authors for peerreviewed scientific publications in 16 international neurosurgical journals from 2002 to 2019 (selected by $h$-index and inclusive of journals publishing author first names). To account for known publication explosion effects occurring during this same period (including even in the journals studied, only 7 of which were in publication at the start of the study period), the authors assessed publication rates year-by-year. Some journals represented subspecialties of neurosurgery (pediatric neurosurgery, spinal surgery, and stereotactic and functional neurosurgery, specifically). They further studied the Journal of Neurosurgery from 1944 through 2019. Large international name/gender relational databases were used to assign gender to authors, including an especially large database incorporating names in multiple languages and nicknames, for those names not easily assigned by the use of the two more readily available but much smaller databases. Only 3.9\% of names were unable to be assigned a gender utilizing this methodology.

The authors acknowledged that there may be bias introduced into their findings regarding overall publication productivity, because they did not include publications in nonneurosurgical publications. Publications associated with work in neurosciences or related medical fields were not included, even from high-impact journals such as $\mathrm{Sci}$ ence, Nature, New England Journal of Medicine, Journal of the American Medical Association, and other highquality neuroscience journals. Furthermore, many subspecialists in neurosurgery commonly publish in journals from related fields such as trauma, neurology, vascular disease, and pediatrics.

The use of big data to formulate assessments on such a complicated issue is novel and interesting, but rather than draw specific conclusions that are inferential, this study should serve as an impetus to analyze the influence of a variety of factors further. The authors rightly identify the current limitations of this methodology, in addition to highlighting the potential for its use with ever-growing digital database availability.

No assumptions were made about the medical discipline of the authors, representing a limitation as far as some of the discussion about academic advancement of women neurosurgeons is concerned, but the main question of accessibility to publication in neurosurgical journals by women (regardless of discipline or career stage) was the primary question being addressed. Likewise, the status of authors as students was not assessed. Given the increasing pressure to publish for medical students with an interest in matching into neurosurgical training programs over this same time period, it is likely that at least some percentage of these papers was authored by medical students. A number of these authors may not have ultimately entered the profession of neurosurgery, in addition to the possible inclusion of graduate students and physicians or scientists in other disciplines, making inferences about proportionality to women neurosurgery residency trainees less relevant. While these concepts represent limitations of the current study, they also represent areas of potential future study.

The authors did make some assumptions that introduce some uncertainty into the conclusions drawn. One such 
assumption was that first authorship denoted junior career or mentee status. Corresponding authors were not studied, and the conventions for the journals studied with respect to last authorship (which may vary) were not described. Last authorship was presumed to mean senior authorship for the purposes of this analysis, which, to be fair, has been done in other similar analyses in the literature, but it may not be accurate. Author order, particularly beyond first authorship, is one of the grayest areas in medical publishing. Entire books have been devoted to this subject, and proper attribution becomes especially confusing when the first author is also the senior scientist or the work represents, for example, multidisciplinary or interdisciplinary collaboration. Finally, last/senior authorship was assumed to be a surrogate for mentorship to the first author, an arguable point, even if the last author was senior and the first author was junior. There are numerous scenarios in which legitimate contributions to the work supporting designation as first and last authors may occur without any significant mentorship relationship or even with a reverse mentor/ mentee relationship. Nonetheless, the findings are notable and bring up areas that would benefit from additional clarity going forward, particularly the finding of increased likelihood of the first author being a woman when the last author was also a woman.

One other point that bears discussion is the reliance on the proportion of trainees as a key comparator in the Discussion section of this article, which must be contextualized. This was possibly done due to better accessibility of reliable data for trainees than for the proportion of women in practice, the latter being a notoriously difficult data set to access, particularly outside of academics. Furthermore, the proportion of women trainees referenced was only for trainees in the United States, and international journals were included in the analysis from areas where the proportion of female trainees may be different. Even if the assumption that last authorship denotes senior authorship is accurate, and authors are assumed to be in the profession of neurosurgery, the real denominator for proportional analyses of that data set would then be practicing neurosurgeons and, presumably (although not exclusively), a subset of those who are involved in academics to at least some degree, given both an interest in publishing and access to coauthors/coinvestigators as relative prerequisites to publishing.

Time lag is a real issue influencing the number of women in neurosurgical practice who are available to act in a senior capacity, as acknowledged in the article. In simple terms, the proportion of female neurosurgeons available to act in a senior capacity would be diluted compared with the proportion of women in training, given the steady increases witnessed in women matriculating into practice over the years. This effect would be diluted even further at the most senior ranks, given that current female senior neurosurgeons were trained during a period when it was unusual to complete a neurosurgical residency and even rarer to seek careers in academic neurosurgery. As the authors point out, analyses of women neurosurgeons' ascendance through the academic ranks have been performed separately. These types of analyses should be referenced as more definitive assessments of academic progress, and the use of last authorship in neurosurgical journals as a surrogate for neurosurgical career progression should be done with caution, especially because there is no information presented herein to even identify these authors as neurosurgeons.

Another study examining first and last authorship, but using the Accreditation Council for Graduate Medical Education and American Association of Medical Colleges data set over a similar time frame (2000-2017), found that women in 13 randomly selected surgical specialties had research publication rates proportional to their representation in the field (derived from both resident and faculty numbers). ${ }^{3}$ Similarly, a study of academic neurosurgeons demonstrated no significant differences in $h$-index between women and men when controlled for rank (assistant, associate, and full professor), despite overall higher rates among men, accounted for by their longer representation in the field. ${ }^{4}$

Even if publication rates are proportional to representation, or similar between women and men, it still behooves our profession to encourage academic productivity in women neurosurgeons. Many issues may impact publication pursuits by women and bear consideration in their mentorship. In a now well-known exposition from 2014 titled "The confidence gap,"5 a variety of scientific studies on self-perception and confidence in science and other disciplines were discussed relative to gender differences. The upshot was that women can tend to underestimate their abilities relative to similar male counterparts and as a result may tend to overprepare. It is plausible that rates of publication correlate to submission attempts and that a tendency toward overpreparation and perfectionism may hold women back when it comes to submitting works for publication. Networking and other collaboration opportunities are, of course, additional important contributing factors.

Interestingly, Taha et al. cited another study showing that, despite increased fellowship completion rates by women neurosurgeons, scholarly activities lag. This may be indicative of the overpreparation phenomenon on another front, with women fellows focusing more on their technical preparation rather than on their academic productivity during their advanced training. Incidentally, Taha noted that the journal with the lowest proportion of female authorship is one focused on technical aspects.

Overpreparation may be reinforced by harsher judging criteria for women in technical fields. Resident evaluations by faculty ${ }^{6}$ and faculty evaluations by residents ${ }^{7}$ have been shown to be lower for women than their male counterparts in surgery. This could represent bias or holding women to higher standards in fields traditionally dominated by men, either of which could contribute to attrition of women in academics unrelated to scientific publication.

Taha et al. also discussed the presence of females on neurosurgical journal editorial boards, and here the presumption that academic publication is predictive of inclusion seems more plausible, as those with higher publication rates may be more likely to be considered as expert in a particular research field, scientific analysis, and technical writing. However, utilizing publication rates as the single largest predictor of academic leadership is perhaps 
not as strong an argument, especially given conflicting data in the literature and the multifactorial nature of academic promotion and tenure acquisition. Women may tend to demonstrate leadership and contribute academically in ways other than publication, including involvement in campus committees, educational curricula development, group work, and other activities that may be less highly valued than scientific research in certain scenarios but that nonetheless are critical and help position them for academic advancement.

Other issues, such as well-known disparities in compensation, may influence women surgeons as to the prioritization of their time and efforts, even in academia-perhaps especially so given the overall lower compensation rates in academic medicine than in other practice models and the recent trends in surgical volume pressures and teaching demands. Practice patterns and referral networks have been shown to be different between female and male surgeons within the same specialty, further confounding time management and prioritization. Taken together, all of these findings suggest that progression in academic rank and leadership is multifactorial and includes influences beyond research publication productivity.

In summary, the authors used a novel big data approach to study a very complex and nuanced issue. What can accurately be gleaned from the study (provided that the gender assignment methodology is sound) is that, over time between 2002 and 2019, women authors in the first and last authorship slots have been increasing proportional to the total number of publications in the 16 neurosurgical journals studied, some more than others. Furthermore, this trend is supported in a case study of the Journal of Neurosurgery since its inception in 1944, with a slowdown in last authorship occurring around 1994 but with ongoing increases in first authorship persisting to the end of the study period.

The authors argue that an increased presence of women in the profession is necessary but not sufficient to promote equal opportunity in academic neurosurgery, a suggestion borne out in the emerging body of literature on this subject. Barrier identification and elimination as well as increased recruitment are mentioned as potential solutions, and these are certainly very important strategies. The au- thors nicely delineate differences between mentorship and sponsorship, both of which are also important for career advancement.

This study is an important contribution and should be utilized to inform more detailed future analyses of publication rates, barriers to publication, relationships of publication rates and $h$-indices to academic advancement, and other issues that affect equity and diversity in neurosurgery, thereby facilitating "what remains to be done."

https://thejns.org/doi/abs/10.3171/2020.12.FOCUS201102

\section{References}

1. Des Jardins J. Marie Curie's passion. Smithsonian Magazine. October 2011. Accessed January 13, 2021. https: //www.smithsonianmag.com/history/madame-curiespassion-74183598/

2. Taha B, Sadda P, Winston G, et al. Increases in female academic productivity and female mentorship highlight sustained progress in previously identified neurosurgical gender disparities. Neurosurg Focus. 2021;50(3):E3.

3. Bernardi K, Lyons NB, Huang L, et al. Gender disparity in authorship of peer-reviewed medical publications. Am J Med Sci. 2020;360(5):511-516.

4. Tomei KL, Nahass MM, Husain Q, et al. A gender-based comparison of academic rank and scholarly productivity in academic neurological surgery. J Clin Neurosci. 2014;21(7): 1102-1105.

5. Kay K, Shipman C. The confidence gap. The Atlantic. May 2014. Accessed January 13, 2021. https://www.theatlantic. com/magazine/archive/2014/05/the-confidence-gap/359815/

6. Gerull KM, Loe M, Seiler K, et al. Assessing gender bias in qualitative evaluations of surgical residents. Am J Surg. 2019; 217(2):306-313.

7. Fassiotto M, Li J, Maldonado Y, Kothary N. Female surgeons as counter stereotype: the impact of gender perceptions on trainee evaluations of physician faculty. J Surg Educ. 2018; 75(5):1140-1148.

\section{Disclosures}

The author reports no conflict of interest.

\section{Correspondence}

Shelly D. Timmons: stimmons@mac.com.

INCLUDE WHEN CITING

DOI: $10.3171 / 2020.12$.FOCUS201102. 